\title{
MODIFICATION OF RECRYSTALLIZATION TEMPERATURE OF URANIUM DIOXIDE IN FUNCTION OF BURN-UP AND ITS IMPACT ON FISSION GAS RELEASE
}

\author{
M. SZUTA ${ }^{a}$ AND M.S. EL-KOLIEL ${ }^{b}$ \\ ${ }^{a}$ Institute of Atomic Energy, 05-400 Otwock-Świerk, Poland \\ ${ }^{b}$ Atomic Energy Authority, Reactors Department, 13759 Cairo, Egypt
}

In the present paper it is assumed that the recrystallization temperature of uranium dioxide decreases with burn-up. Two opposing effects of enhancement and inhibition of irradiation damage introduced by fission effect on grain growth are described. Mathematical model of fission gas release from the $\mathrm{UO}_{2}$ fuel affected by grain growth is presented. Theoretical results are compared with the experimental data.

PACS numbers: 25.85.Ec, 66.30.Lw

\section{Introduction}

Out-of-pile experiments show that during annealing the irradiated $\mathrm{UO}_{2}$ samples bursts of fission gas release occur [1]. After a small burst release at relatively low temperature, a large burst release appears at high temperature. The critical temperature for high temperature burst release is about $1800^{\circ} \mathrm{C}$ for low burn-up (about $7 \mathrm{MWd} / \mathrm{kgU}$ ) and decreases to about $1500^{\circ} \mathrm{C}$ for high burn-up (30 MWd/kgU).

The point defects induced by radiation begin to recover at $450-650^{\circ} \mathrm{C}$ and are completely almost recovered above $850^{\circ} \mathrm{C}$, while defect clusters of dislocations and small intragranular bubbles require $1150-1450^{\circ} \mathrm{C}$ [2]

Thermal recovery of radiation defects and microstructure change in irradiated $\mathrm{UO}_{2}$ fuels studied by X-ray diffraction and transmission electron microscopy lead to the conclusion that the gas release kinetics from irradiated $\mathrm{UO}_{2}$ is determined by the kinetics of thermal recovery of the radiation induced defects.

If the point defects, defect clusters of dislocations and small intragranular bubbles are thermally recovered at the temperatures below $1450^{\circ} \mathrm{C}$, a natural question concerns nature of forces which immobilise the noble gases. Hence an additional trapping process of inert gas atoms with the uranium dioxide material is suspected to occur. 
The process of strong binding of the fission gas fragments with the irradiation defects is described in the literature as a process of chemical interaction with $\mathrm{UO}_{2}$ [3]. It is assumed that the vicinity of the fission fragment trajectory is the place of intensive irradiation induced chemical interaction of the fission gas products with $\mathrm{UO}_{2}[3]$.

We can further assume that above a limiting value of fission fluency (burn-up) a more intensive process of irradiation induced chemical interaction occurs. Significant part of fission gas product is thus expected to be chemically bound in the matrix of $\mathrm{UO}_{2}$.

Furthermore, it is expected that the gas can be released only in the process of recrystallization. The higher fission fluency (burn-up) the higher amount of gas should be released and the lower recrystallization temperature should be observed. Out-of-pile experiments [1] support this assumption since the critical temperature of fission gas burst release during annealing decreases with burn-up.

The critical temperature decrease with burn-up suggests that the recrystallization temperature of $\mathrm{UO}_{2}$ is changed by the process of chemical interaction. It is clear that during irradiation the grain growth should be observed above the recrystallization temperature and division of grains below the temperature should be observed when saturation is obtained. This means further that the recrystallized region will be adjacent to the subdivided grain region and the appearance of interface between the two regions will be determined by the recrystallization temperature. It can also be expected that in the recrystallized grains the defects are swept out.

This seems to be natural since the chemically bound fission gas atoms substituting for example uranium atom in the crystallographic lattice can form weak facets. The recrystallization temperature should decrease the more fission gas atoms are retained. At certain saturation condition division of the grains can occur and the increase in fission gas products release may be expected.

The fact that the process of grain division for high burn-up $(70-80 \mathrm{MWd} / \mathrm{kgU})$ forms an extremely fine structure to a temperature as high as $1100^{\circ} \mathrm{C}$ and that the decrease in fission gas concentration in the fuel [4] supports this concept. Also the recrystallized grain region is found to be adjacent to the subdivided grain region and in the recrystallized grain no defects or bubbles are observed [5].

The decrease in critical temperature to about $1100^{\circ} \mathrm{C}$ for over $1 \%$ fractional fission gas release from the fuel and for high burn-up, reported by Vitanza et al. [6], well correlates with the experiments [1] and [4] mentioned above. This also gives evidence for the concept of chemical interaction of the fission gas atoms with the atoms of the fuel.

In the following, we assume further that all the retained gas atoms in the lattice are released from the volume of recrystallized grains.

Assuming that the Vitanza curve [6] describes the change of uranium dioxide recrystallization temperature we can say that the grain growth rate depends on the burn-up in the way given by the best fit of the grain size change with the curve. 


\section{Modification of grain growth equation}

The grain growth model of Ainscough et al. [7] is generally considered to be the best available one. It assumes the following equation of grain growth rate:

$$
\frac{\mathrm{d} D}{\mathrm{~d} t}=k\left(\frac{1}{D}-\frac{1}{D_{\mathrm{m}}}\right)[\mu \mathrm{m} / \mathrm{h}],
$$

with

$$
\begin{aligned}
& k=5.24 \times 10^{7} \exp \left(-\frac{2.67 \times 10^{5}[\mathrm{~J} / \mathrm{mol}]}{\mathrm{RT}}\right)\left[\mu \mathrm{m}^{2} / \mathrm{h}\right], \\
& D_{\mathrm{m}}=2.23 \times 10^{3} \exp \left(-\frac{7620[\mathrm{~K}]}{\mathrm{T}}\right)[\mu \mathrm{m}],
\end{aligned}
$$

where $D$ - grain diameter $[\mu \mathrm{m}], D_{\mathrm{m}}$ - limiting grain size $[\mu \mathrm{m}]$ at which grain growth ceases, $R$ - the gas constant equal to $8.314 \mathrm{~J} /(\mathrm{mol} \mathrm{K}), T$ - temperature $[\mathrm{K}], t$ - time $[\mathrm{h}]$.

To solve Eq. (1) it is necessary to know the initial grain size.

It was found that the concentration of fission products is an important factor in retarding the grain growth [7].

Equation (1) was modified [7] to allow for the increasing retarding effect of fission products by replacing $D_{\mathrm{m}}$ by the limiting grain size by $D_{\mathrm{m}}^{\prime}$, dependent on temperature and burn-up

$$
D^{\prime}{ }_{\mathrm{m}}=\frac{D_{\mathrm{m}}}{f(B)}=\frac{D_{\mathrm{m}}}{1+0.002 B},
$$

where $B$ is the burn-up in $\mathrm{MWd} / \mathrm{tU}$.

Comparing the empirical data [8] of limiting grain size influenced by irradiation conditions with the limiting grain size described by Eq. (2) we came to the conclusion that the function $f(B)$ dependent on burn-up is

$$
f(B)=1+(0.00002 \pm 0.000006) B \text {. }
$$

The coefficient $k$ in the simple rate Eq. (1) describes the term of grain growth rate dependent on temperature. However, the out-of-pile annealing experiments referring to the burst of fission gas release [1], the decrease in critical temperature for fractional fission gas release from the fuel above $1 \%$ [6] and the in-reactor experiments of grain growth in function of temperature [7] for different burn-ups imply that the coefficient $k$ should also depend on burn-up. Equation (1a) presents the coefficient $k$ for non-irradiated $\mathrm{UO}_{2}$ fuel. Therefore the temperature in this equation (1a) should be increased by the value dependent on burn-up in order to obtain the Vitanza curve. It means that the recrystallization temperature occurs at earlier temperatures when the burn-up is higher. Finally, we evaluated that the grain growth constant $k$ in the simple rate equation obtains the form

$k=5.27 \times 10^{7} \exp \left\{-\frac{2.67 \times 10^{5}}{R\left[T+371\left[1-\exp \left(-\frac{B}{2700}\right)+\frac{560}{40000} B\right]\right]}\right\}\left[\mu \mathrm{m}^{2} / \mathrm{h}\right]$.

The above considerations show that the irradiation damage (burn-up) introduced by fission events have two opposing effects on grain growth. The large 
concentration of fission gas atoms in the lattice introduced in fission spikes enhances the transfer of atoms across a boundary, increasing the rate of growth.

The higher is burn-up, the higher is the value of $k$ and consequently the higher is the grain growth rate.

Conversely, the impurities (burn-up) introduced by fission inhibit growth. The higher is burn-up the lower is the limiting grain size (see Eq. (2)).

Solving numerically the differential equation (1) with the help of the modified Runge-Kutta integration method using the new grain growth rate constant (4) we obtain a reasonable agreement with the experimental data of in-reactor grain growth versus temperature for two different burn-ups - see Fig. 1 and Fig. 2. $10 \%$ of grain size increase for burn-up $B=6560 \mathrm{MWd} / \mathrm{tU}$ occurs at about $1300^{\circ} \mathrm{C}$ (Fig. 1) and for burn-up $B=12865 \mathrm{MWd} / \mathrm{tU}$ at about $1200^{\circ} \mathrm{C}$ (Fig. 2). This correlates very well with the Vitanza curve.

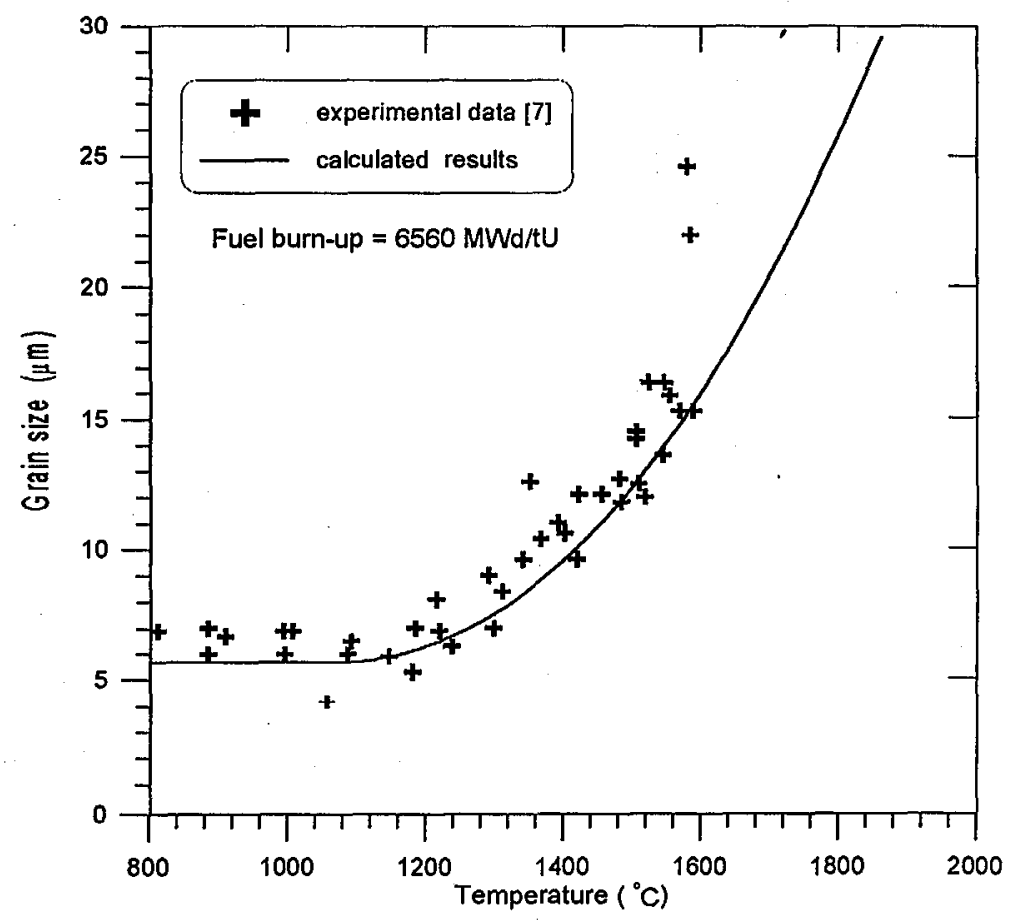

Fig. 1. Comparison of measured and calculated temperature dependence of the fuel grain growth for fuel burn-up $6560 \mathrm{MWd} / \mathrm{tU}$.

The same above principle of temperature appointment at $10 \%$ grain size increase allows us to invent the curve of recrystallization temperature versus burn-up (Fig. 3) from the family curves of grain growth in function of temperature for different burn-ups (Fig. 4). Fitting the curve of recrystallization temperature in function of burn-up with the Vitanza curve is fairly good but for low burn-up. As Vitanza curve describes the critical temperature of fractional fission gas release from fuel above $1 \%$ in function of burn-up [6] and for low burn-up the single gas 


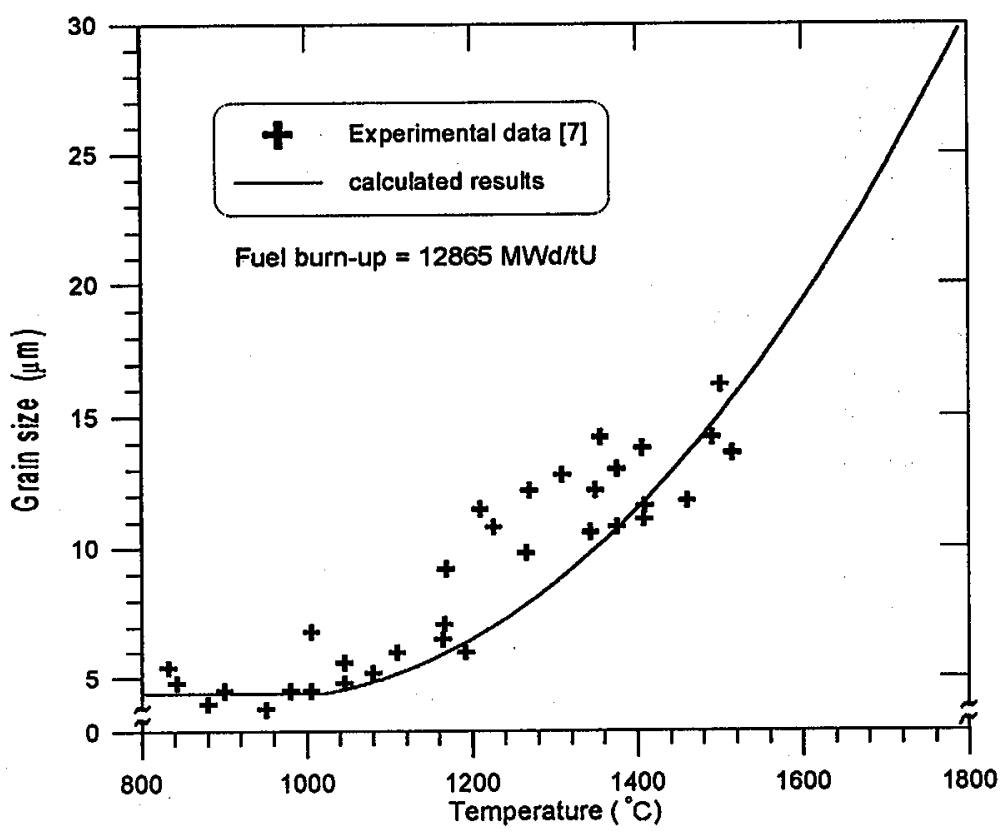

Fig. 2. Comparison of measured and calculated temperature dependence of the fuel grain growth for fuel burn-up $12865 \mathrm{MWd} / \mathrm{t} U$.

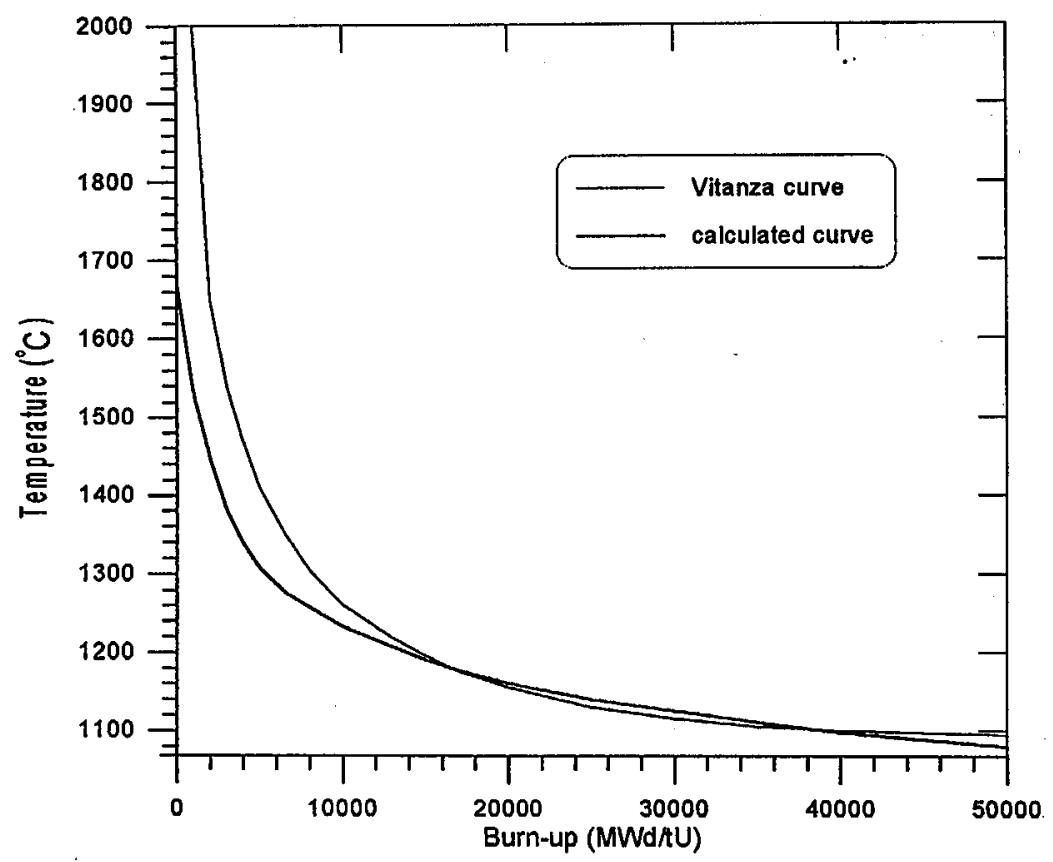

Fig. 3. Comparison of the calculated dependence of the recrystallization temperature on burn-up with the Vitanza curve [6]. 


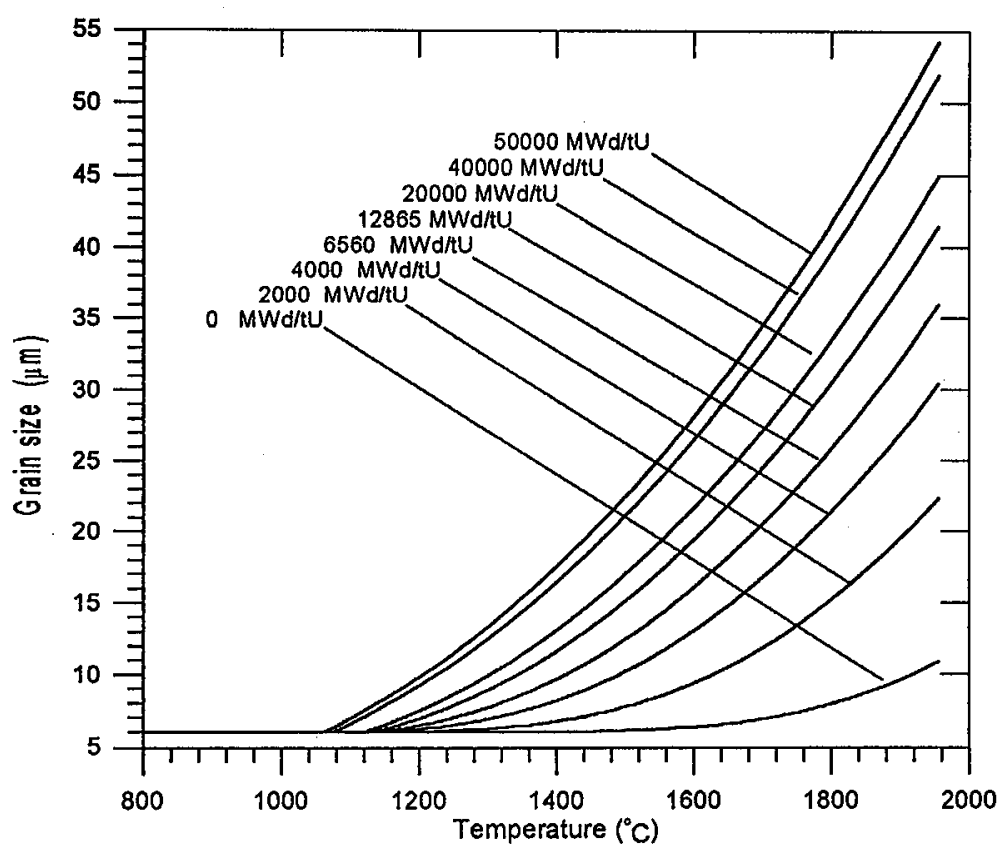

Fig. 4. Fuel grain growth versus fuel temperature for various values of the fuel burn-up.

atom diffusion is most significant in fission gas release [9], it means the process of recrystallization for low burn-up is negligible. Therefore the comparison of Vitanza curve with the recrystallization temperature versus burn-up has no basis for low burn-up.

\section{Algorithms of fission gas release due to recrystallization of $\mathrm{UO}_{2}$ grains}

It is generally accepted that most of the insoluble inert gas atoms of xenon and krypton produced during fissioning are retained in the fuel irradiated at a temperature lower than the threshold [9-17]. We assume that most of the gas atoms are retained in the matrix of grains being there immobilised or are precipitated into small fission gas bubbles.

We assume further that the retained gas atoms in the fuel are released from the volume of the recrystallized grains.

The defect trap model of fission gas behaviour in $\mathrm{UO}_{2}$ fuel described in the papers $[9,18-20]$ should be supplemented by the description of the grain growth process. In the model it is assumed that the fission gas atoms trapped in the matrix of $\mathrm{UO}_{2}$ and that trapped in bubbles exist side by side with the intermediate gas, which consists of the gaseous fission fragments and the kinetically excited fission gas products. The processes of re-solution, knock-out and bubble diffusion are used.

It is well known that the grain growth in polycrystalline materials is caused by a preferential shrinkage of smaller grains due to their relatively smaller radii of curvature. An average number of grains, $N_{0}$, in a unit volume is 


$$
N_{0}=\frac{1-p / 100}{\frac{4}{3} \pi\left(D_{0} / 2\right)^{3}}
$$

where $p-$ porosity in $\%, D_{0}-$ initial grain diameter.

At the elevated temperature the number of grains, $N$, in the unit volume is fixed by the limiting grain size, $D_{\mathrm{m}}$ :

$$
N=\frac{1-p / 100}{\frac{4}{3} \pi\left(D_{\mathrm{m}} / 2\right)^{3}}
$$

The initial grain size, $D_{0}$, is easily measurable while the limiting grain size after the grain growth, $D_{\mathrm{m}}$, is determined from Eq. (2).

In order to complete the set of differential equations of the defect trap model of fission gas behaviour, the release rate of re-soluted gas and trapped in the bubbles is to be determined. Multiplying the volume rate of grain by the concentration of re-soluted gas atoms in the matrix, $M_{\mathrm{r}}$, and trapped gas atoms in the bubbles, $M_{\mathrm{tr}}$, we obtain the release from one grain, $R_{\mathrm{go}}$ :

$$
R_{\mathrm{go}}=\frac{1}{2} \pi\left(M_{\mathrm{r}}+M_{\mathrm{tr}}\right) D^{2} \frac{\mathrm{d} D}{\mathrm{~d} t}
$$

where $\mathrm{d} D / \mathrm{d} t$ is determined from Eq. (1) and Eq. (2), (3) and (4).

The product of release rate from one grain, $R_{\mathrm{go}}$, and the number of grains, $N$, at elevated temperature, defined by Eq. (6), determines the release rate from a unit volume.

It is assumed that the total surface area versus burn-up does not change during the process of grain growth.

Finally, the defect trap model presented previously [9, 18-20] can be supplemented with the description of fission gas behaviour due to grain growth process, according to the aforementioned assumptions. The coupled equations of such model are solved numerically using the modified Runge-Kutta method and the explicit finite-difference technique - Crank-Nicolson scheme.

\section{Comparison with experiments}

When grain growth occurs, the gases are released more rapidly than they are released by knock-out process.

Two cases were calculated in order to examine the influence of grain growth on fission gas release. The calculations have been carried out for the case of the temperature $1100^{\circ} \mathrm{C}$ which required taking the grain growth into account, and the other, for the temperature $1000^{\circ} \mathrm{C}$, when no grain growth occurs. The initial grain size of $8 \mu \mathrm{m}$ and the fission rate $f=10^{14}$ fissions $/\left(\mathrm{cm}^{3} \mathrm{~s}\right)$ were used in the calculations. Figure 5 displays the results together with the experimental data presented in Ref. [21].

In Fig. 6 we show the calculation of fractional fission gas release (release/birth) versus burn-up for three temperatures $\left(877^{\circ} \mathrm{C}, 1077^{\circ} \mathrm{C}\right.$ and $\left.1327^{\circ} \mathrm{C}\right)$ which are compared with the experimental results presented in Ref. [14]. The experimental results are grouped into two temperature ranges: $877-1077^{\circ} \mathrm{C}$ and $1077-1327^{\circ} \mathrm{C}$.

Both, Fig. 5 and Fig. 6, show a reasonably good agreement of the calculated and measured gas release. Comparing the figures we can see that the fractional fission gas release for the temperature $1077^{\circ} \mathrm{C}$ is higher than for the $1100^{\circ} \mathrm{C}$. This peculiarity is explained by the influence of initial grain size on fission gas release. 


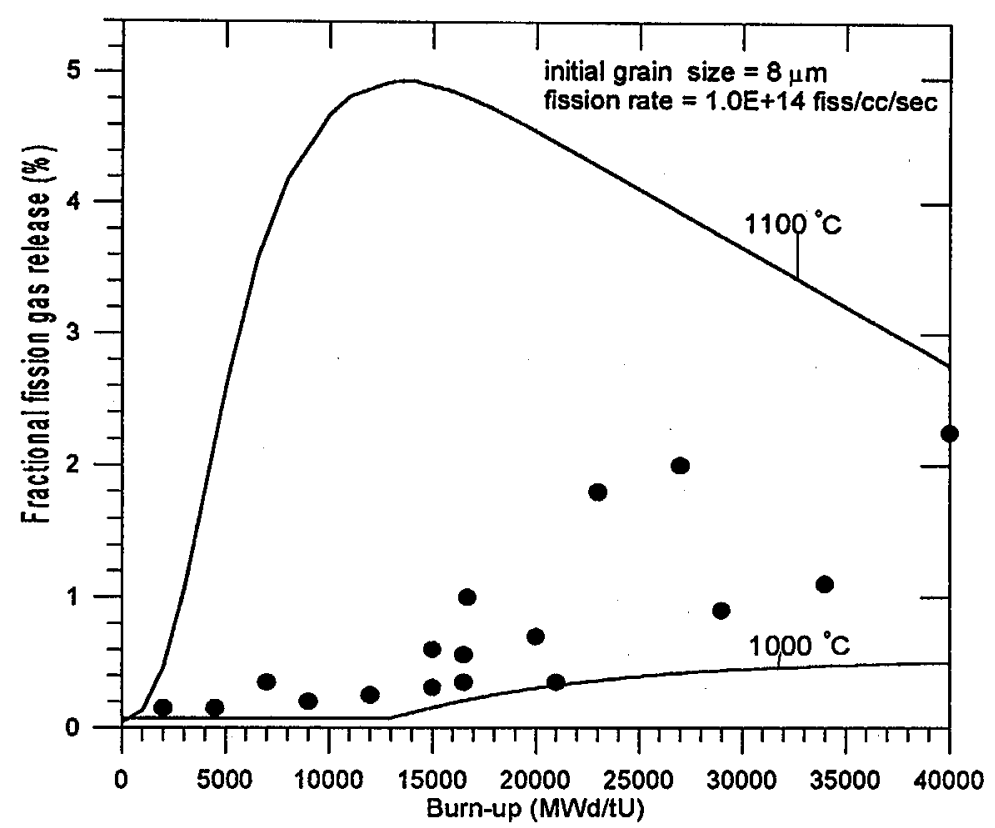

Fig. 5. Comparison of the fractional fission gas release as a function of burn-up with the experimental data taken from Fig. 2 of Ref. [21].

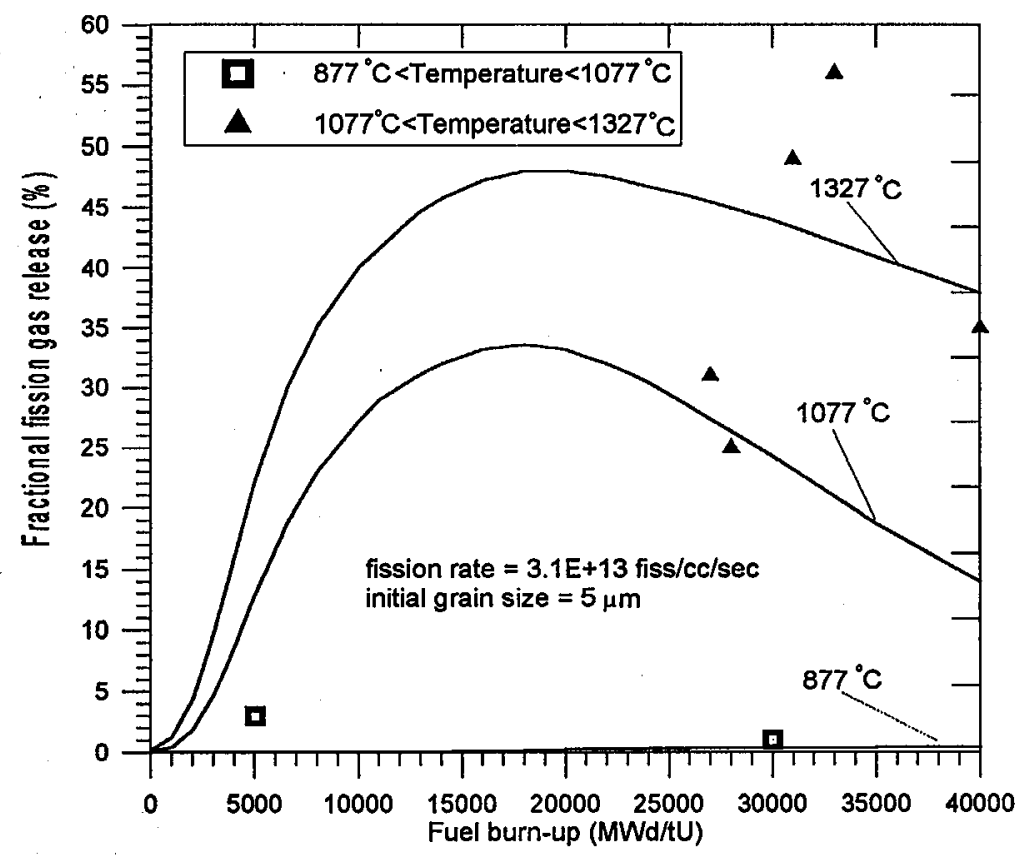

Fig. 6. Comparison of the fractional fission gas release as a function of burn-up with the experimental data taken from Fig. 3 of Ref. [14]. 


\section{Conclusions}

The modification of grain growth equation is performed by taking into account two opposing effects of enhancement and inhibition of irradiation damage introduced by the fission effect on the grain growth. The defect trap model of fission gas behaviour is improved by including description of the grain growth process. The larger is the initial grain size the smaller is the fission gas release. The calculated and experimental results are remarkably close to each other, and therefore give us confidence in the model. In particular it supports the assumption that the Vitanza curve presents the recrystallization temperature of uranium dioxide grains.

\section{References}

[1] K. Une, Sh. Kashibe, J. Nucl. Sci. Technol. 27, 2002 (1990).

[2] Y. Nogita, K. Une, J. Nucl. Sci. Technol. 30, 900 (1993).

[3] D.A. McInnes, P.W. Winter, J. Phys. Chem. Solids 49, 143 (1988).

[4] K. Lassman, C.T. Walker, J. Van de Laar, F. Lindstrom, J. Nucl. Mater. 26, 1 (1995).

[5] K. Nogita, K. Une, Nucl. Instrum. Methods Phys. Res. B 91, 301 (1989).

[6] C. Vitanza, E. Kolstad, U. Gracioni, in: Proc. Am. Nucl. Soc., Topical Meeting on Light Water Reactors Fuel Performance, American Nuclear Society, Portland (OR) 1979, p. 361.

[7] J.B. Ainscough, B.W. Oldfield, J.O. Ware, J. Nucl. Mater. 49, 117 (1973/74).

[8] C. Bagger, M. Mogensen, C.T. Walker, J. Nucl. Mater. 211, 11 (1994).

[9] M. Szuta, J. Nucl. Mater. 210, 178 (1994).

[10] H. Zimmermann, J. Nucl. Mater. 75, 154 (1978).

[11] R.J. White, M.O. Tucker, J. Nucl. Mater. 118, 1 (1983).

[12] T. Nakajima, H. Saito, Nucl. Eng. Des. 101, 267 (1987).

[13] K. Hiramoto, K. Miki, M. Nakamura, Nucl. Eng. Des. 81, 395 (1984).

[14] K. Ito, R. Iwasaki, Y. Iwano, J. Nucl. Sci. Technol. 22, 129 (1985).

[15] J. Rest, A.W. Cronenberg, J. Nucl. Mater. 150, 203 (1987).

[16] J.R. MacEwan, W.H. Stevens, J. Nucl. Mater. 111, 77 (1964).

[17] I.L.F. Ray, H. Thiele, Hj. Matzke, J. Nucl. Mater. 188, 90 (1992).

[18] M. Szuta, J. Nucl. Mater. 58, 278 (1975).

[19] M. Szuta, J. Nucl. Mater. 97, 149 (1981).

[20] M. Szuta, J. Nucl. Mater. 130, 434 (1985).

[21] C.C. Dollins, J. Nucl. Mater. 49, 10 (1973/74). 